\title{
Protective Capacity of Statins during Pneumonia Is Dependent on Etiological Agent and Obesity
}

\author{
Erik A. Karlsson, Stacey Schultz-Cherry and Jason W. Rosch* \\ Department of Infectious Diseases, St. Jude Children's Research Hospital, Memphis, TN, United States
}

Acute respiratory infections are a leading cause of death worldwide. Clinical data is conflicted regarding whether statins improve outcomes for pneumonia. Potential confounding factors including specific etiology of pneumonia as well as obesity could potentially mask protective benefit. Obesity is a risk factor for high cholesterol, the main target for statin therapy. We demonstrate that statin intervention conferred no protective benefit in the context of wild-type mice regardless of infectious agent. Statin intervention conferred either a protective benefit, during influenza infection, or detrimental effect, in the case of pneumococcal infection, in obese animals. These data suggest etiology of pneumonia in the context of obesity could be dramatically altered by the protective effects of statin therapy during bacterial and viral pneumonia.

Keywords: Streptococcus pneumoniae, influenza, statin, obesity, pneumonia

\section{OPEN ACCESS}

Edited by:

W. Edward Swords,

University of Alabama at Birmingham,

United States

Reviewed by:

Kirsty Renfree Short,

The University of Queensland,

Australia

Julie McAuley,

University of Melbourne, Australia

*Correspondence:

Jason W. Rosch

jason.rosch@stjude.org

Received: 15 November 2017 Accepted: 31 January 2018

Published: 15 February 2018

Citation:

Karlsson EA, Schultz-Cherry S and Rosch JW (2018) Protective Capacity

of Statins during Pneumonia Is

Dependent on Etiological Agent and

Obesity.

Front. Cell. Infect. Microbiol. 8:41. doi: 10.3389/fcimb.2018.00041

\section{INTRODUCTION}

Statins (3-hydroxy-3-methylglutaryl coenzyme A reductase inhibitors) lower circulating lipid levels and decrease risk of cardiovascular disease. Statins also have a number of pleiotropic effects including anti-inflammatory and immunomodulatory properties that may confer benefit during infection (Jain and Ridker, 2005; Fedson, 2006). Several retrospective clinical studies have attempted to observe the beneficial effects of statins in regards to infection with conflicting conclusions (Mortensen et al., 2005, 2008, 2012; van de Garde et al., 2006; Frost et al., 2007; Schlienger et al., 2007; Chalmers et al., 2008; Thomsen et al., 2008; Dublin et al., 2009; Myles et al., 2009; Douglas et al., 2011; Vinogradova et al., 2011; Yende et al., 2011; Nielsen et al., 2012; Novack et al., 2012; Rothberg et al., 2012; Doshi et al., 2013). The majority of these studies suggest a beneficial effect (Mortensen et al., 2005, 2008, 2012; van de Garde et al., 2006; Frost et al., 2007; Schlienger et al., 2007; Chalmers et al., 2008; Thomsen et al., 2008; Myles et al., 2009; Douglas et al., 2011; Vinogradova et al., 2011; Nielsen et al., 2012; Novack et al., 2012; Rothberg et al., 2012; Doshi et al., 2013); however, several have found no difference or even a harmful effect of statins on pneumonia-related morbidity and mortality (Dublin et al., 2009; Yende et al., 2011). A majority of the studies do not control for pneumonia etiology based on laboratory-confirmed diagnosis (Mortensen et al., 2005, 2008, 2012; van de Garde et al., 2006; Schlienger et al., 2007; Chalmers et al., 2008; Thomsen et al., 2008; Dublin et al., 2009; Myles et al., 2009; Douglas et al., 2011; Vinogradova et al., 2011; Yende et al., 2011; Nielsen et al., 2012; Novack et al., 2012), potentially introducing variable effects of statins due to distinct pathogenic mechanisms of viral and bacterial agents. In addition, the majority of the studies examining the pleiotropic effects of statins usually control for risk factors, such as diabetes and obesity, without factoring them as a separate group that may have altered pathogenesis and course of acute respiratory infection. 
It is becoming increasingly apparent that the metabolic status of the host can profoundly impact infection susceptibility as well as to decrease responses to vaccines. Given that in the United States alone, $68.0 \%$ of the population has a Body Mass Index $(\mathrm{BMI}) \geq 25 \mathrm{~kg} / \mathrm{m}^{2}$ indicating the majority of the population is overweight or obese, the role of obesity is a critical consideration (Flegal et al., 2010). Obesity has been found to be an independent risk factor for influenza severity and mortality, (Karlsson and Beck, 2010) findings effectively modeled in several mouse studies (Smith et al., 2007; Easterbrook et al., 2011; O'Brien et al., 2012). Obesity is also strongly associated with cardiovascular disease risk. Indeed, $80 \%$ of obese individuals exhibit classical metabolic lipid changes and statins are the drug of choice for lowering lipid levels (Tonstad and Despres, 2011). We hypothesized that metabolic status would profoundly impact the protective capacity of statins in the context of respiratory infection. Our data indicates that obesity as well as whether the pneumonia is bacterial or viral in origin as critical determinants for the protective effects of statins in the context respiratory disease.

\section{METHODS}

\section{Ethics Statement}

All experiments involving animals were performed with prior approval of and in accordance with guidelines of the St. Jude Institutional Animal Care and Use Committee. The St Jude laboratory animal facilities have been fully accredited by the American Association for Accreditation of Laboratory Animal Care. Laboratory animals are maintained in accordance with the applicable portions of the Animal Welfare Act and the guidelines prescribed in the DHHS publication, Guide for the Care and Use of Laboratory Animals.

\section{Bacterial and Viral Strains and Growth Conditions}

The Streptococcus pneumoniae D39x (serotype 2) (Francis et al., 2001) pneumococcal strain was grown overnight at $37^{\circ} \mathrm{C}$ in a $5 \%$ $\mathrm{CO}_{2}$ humidified incubator after being inoculated onto tryptic soy agar (TSA) plates supplemented with 3\% sheep blood. Strains were then inoculated directly into semisynthetic liquid culture (CY broth) and grown to log phase before being administered to mice. The influenza A virus A/California/04/2009(A/H1N1pdm) generated by reverse genetics (McAuley et al., 2007), was grown in Madin-Darby canine kidney (MDCK) cells.

\section{Mice Utilized in Cholesterol and Obesity Studies}

Wild-type, female C57/B16 mice and genetically obese, B6.CgLep ${ }^{\circ b} / \mathrm{J}(o b / o b)$ mice were obtained from The Jackson Laboratory, Bar Harbor, ME, USA. ob/ob mice lack the anorexigenic adipokine Leptin which makes them hyperphagic leading to profound obesity. These animals have been used extensively to study both diabetes and obesity phenotypes (Lutz and Woods, 2012).

\section{Statin Treatment}

Mice were maintained on a diet containing $120 \mathrm{ppm}$ simvastatin (Diet \#5053, Purina TestDiet) beginning at age 4 weeks and continuing for 4 weeks. Mock treated animals received a matched diet lacking simvastatin. Following treatment, serum was collected and high-density lipoprotein (HDL), low-density lipoprotein (LDL), triacylglycerol (TAG), and total cholesterol levels were measured to confirm pharmacological benefit. Mice were fed ad libitum and were maintained on the diet throughout the course of the infectious challenges.

\section{Cholesterol Diet}

Mice were placed for 4 weeks on either a high-cholesterol diet (HCD) (15.8\% fat, 1.25\% cholesterol, and $0.5 \%$ cholate, test diet \#90221; Harlan Laboratories, Indianapolis, IN) or a normal diet (ND), which was identical, except for omission of cocoa butter, cholesterol, and cholate (test diet \#95138). Cholesterol levels were measured in serum using the ABX Pentra Cholesterol CP kit (Horiba ABX, Montpellier, France) according to manufacturer guidelines.

\section{Mouse Challenges}

All mice were maintained in BSL2-level, specific pathogen free facilities. All experimental inoculation procedures were conducted under general anesthesia with inhaled isofluorane at $2.5 \%$. Mice were monitored daily for signs of infection.

For bacterial burden and survival studies, bacterial strains were grown in $\mathrm{C}+\mathrm{Y}$ media to an $\mathrm{OD}_{620}$ of 0.4 and diluted according to a previously determined standard curve. Bacteria were introduced into mice (Jackson Laboratory) via intranasal (IN) administration of $10^{7} \mathrm{CFU}$ of bacteria in PBS $(30 \mu \mathrm{L})$. Mice were monitored for disease progression and euthanized via $\mathrm{CO}_{2}$ asphyxiation. Blood for titer determination was collected via tail snip at 24 and $48 \mathrm{~h}$ post-infection and subsequent serial dilution and plating. For the viral challenge, mice were lightly anesthetized with isofluorane and intranasally inoculated with $10^{2} \mathrm{TCID}_{50}$ units of influenza A/H1N1pdm in $25 \mu \mathrm{l}$ PBS. Mice were monitored daily for clinical signs of infection (Morton, 2000) and weighed every $24 \mathrm{~h}$ post-inoculation (pi). Co-infection challenges were performed as previously described (Karlsson et al., 2017). Survival data were analyzed using the Mantel-Cox log rank test in Prism 6. Bacterial and viral titers were compared using non-parametric Mann-Whitney $t$-test in Prism 6.

\section{Viral Titer Determination}

Viral titers from lung homogenates, BALF and nasal washes were determined by $50 \%$ tissue culture infectious dose $\left(\mathrm{TCID}_{50}\right)$ on Manin Darby Canine Kidney (MDCK) cells (Cline et al., 2011). Briefly, MDCK cells were infected with $100 \mu \mathrm{L}$ of 10 -fold serial dilutions of sample and incubated at $37{ }^{\circ} \mathrm{C}$ for $72 \mathrm{~h}$. Following incubation, viral titers were determined by hemaglutination assay using $0.5 \%$ turkey red blood cells and analyzed by the method of Reed and Meunch (1938).

\section{Literature Search Criteria}

To investigate the known literature on the effects of statins on pneumonia outcome and etiology, a comprehensive search of 
the peer-review literature was conducted on PubMed based on a range of key terms including statin (or statin derivatives such as atorvastatin) and pneumonia, respiratory infection, influenza, and bacteria. Papers that met this criteria were then further refined by only choosing articles focused on human trials. Reviews were excluded from the search. These papers were then scrutinized for type of statin used, outcomes, presence of obesity or BMI as a factor in the analysis or outcomes as well as clinical diagnosis of etiology.

\section{RESULTS}

We hypothesized that that the effect of prophylactic statin therapy could have significantly altered benefit depending on the infectious agent, in this case bacterial and viral pneumonia, as well as the obesity status of the host. To test the impact of statins on acute respiratory infection in obesity, wild type and genetically obese mice were given either a statin or a mock diet for 4 weeks. Subsequent serum analysis confirmed a significant reduction in the levels of cholesterol in response to the statin diet, confirming pharmacological benefit (Figure 1A). In addition, benefit was observed in terms of liver function as measured by serum aspartate aminotransferase (AST) levels, though reduction in alanine aminotransferase (ALT) levels was not significant (Figures 1B,C). These data indicate that the statin intervention was effective at the doses administered with expected improvements in physiological parameters.

We next sought to determine if statin intervention would alter the susceptibility of either wild-type or obese mice to respiratory infection. This was initially modeled using an influenza virus challenge. Obese mice were found to demonstrate enhanced susceptibility to influenza infection in concordance with previously published reports (Karlsson and Beck, 2010; Karlsson et al., 2017). Prophylactic statin intervention was found to confer no protective benefit against influenza induced mortality in wild-type animals (Figure 2A). In contrast, obese mice treated with statins were significantly less susceptible to influenza virus with a $40 \%$ increase in survival following infection (Figure 2B). Statin intervention was found to reduce influenza viral burden in the lungs 6 days post-infection though no alteration in viral titers at either earlier time points or in the wild-type animals in response to either mock or statin treatment was observed (Figure 2C). These data indicate that statin intervention may confer protective benefit in the context if influenza mediated pneumonia.

We next sought to determine whether the metabolic-status dependent protection conferred by statin intervention could be extrapolated to other etiological agents of pneumonia, specifically pneumococcal pneumonia. In agreement with previous studies, no significant protection in terms of mortality was observed in wild-type statin treated animals compared to the mock group (Figure 3A). In contrast to the protective capacity observed in the influenza challenge models, obese mice receiving statins were significantly more susceptible to $S$. pneumoniae infection with a significant decrease in survival (Figure 3B). This altered

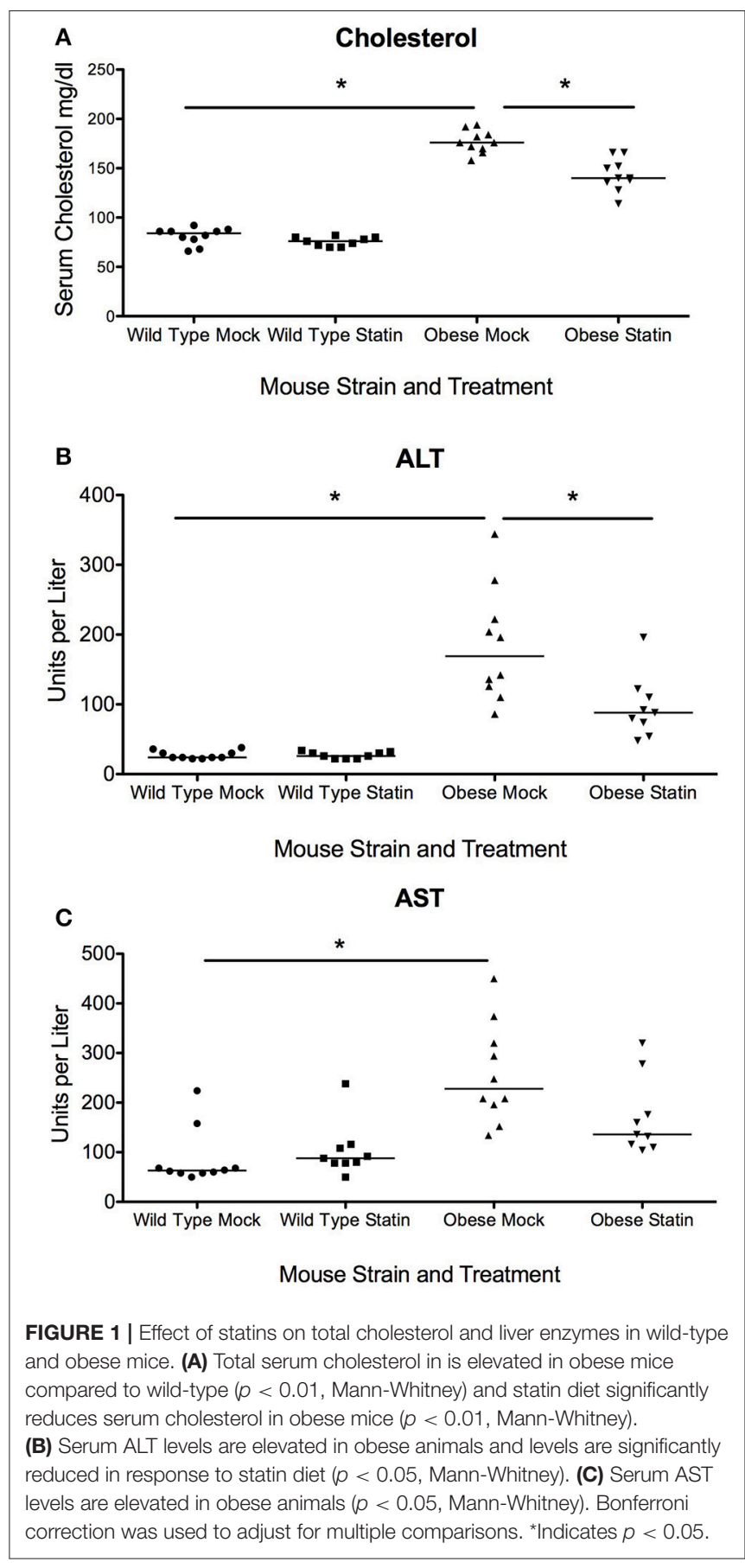

survival was reflected by the relative pathogen burden, as statin treatment increased the level of bacteremia in the obese mice (Figure 3C). Collectively, these data demonstrate distinct responses in terms of mortality for statin-treated obese mice based on the etiology of the pneumonia that was not apparent in the mock treated animals. These data indicate that statin treatment has minimal effect in wild-type animals, but can potentially confer both a protective, in the case of influenza, and a detrimental, in the case of $S$. pneumoniae, effect on survival following infection. 




B Obese Mice - Influenza Challenge


FIGURE 2 | Impact of statin intervention on influenza pathogenesis in wild-type and obese mice. (A) Survival of wild-type mice receiving mock or statin supplemented diet following infection with influenza $(p>0.05$ Mantel log-rank test). (B) Statin intervention significantly ( $p<0.05$ Mantel log-rank test) improved survival in obese mice following influenza infection. $n=10$ mice per group. (C) Statin intervention significantly ( $p<0.05$, Mann-Whitney) decreased influenza viral burden in lungs 6 days post-challenge compared to mock treated animals. Note that statistical comparisons were made between each combination of two treatment groups to determine significance. *Indicates $p<0.05$

These data also call into the question the potential protective mechanism of statins in the context of influenza-mediated pneumococcal superinfection. It has been established both clinically and murine models that prior influenza infection greatly enhances host susceptibility to secondary bacterial infection, particularly with the pneumococcus through a variety of mechanisms (McCullers, 2014). We hypothesized that the opposing effects of statin therapy in obese animals in respect to bacterial and influenza challenge may be ameliorated in the context of co-infection. When mice were challenged in the coinfection model, neither protection nor enhanced susceptibility was observed in the influenza- $S$. pneumoniae co-infected mice, regardless of metabolic status (Figures 4A,B). These data indicate the opposing effects of statins in the context of obesity

\section{A Wild Type Mice - Pneumococcal Challenge}

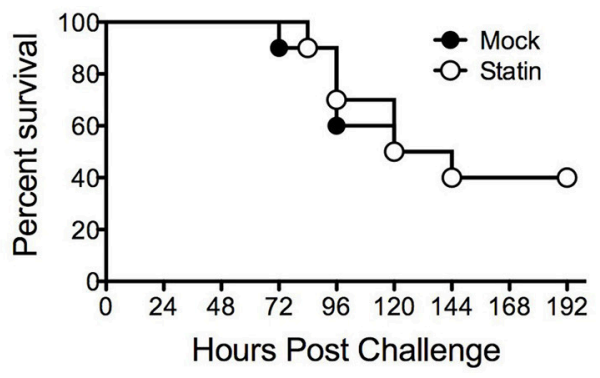

B Obese Mice - Pneumococcal Challenge

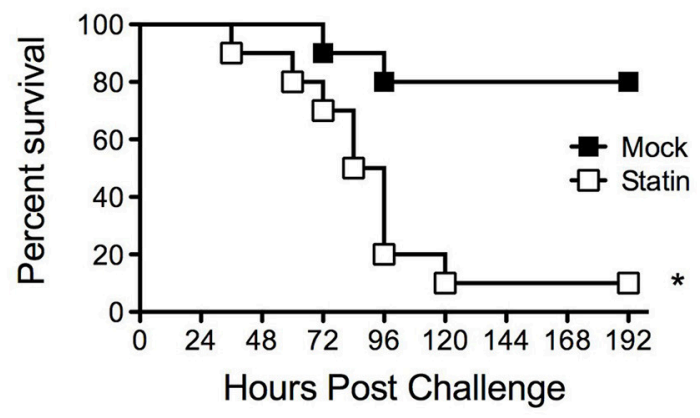

c Bacterial Loads in Blood

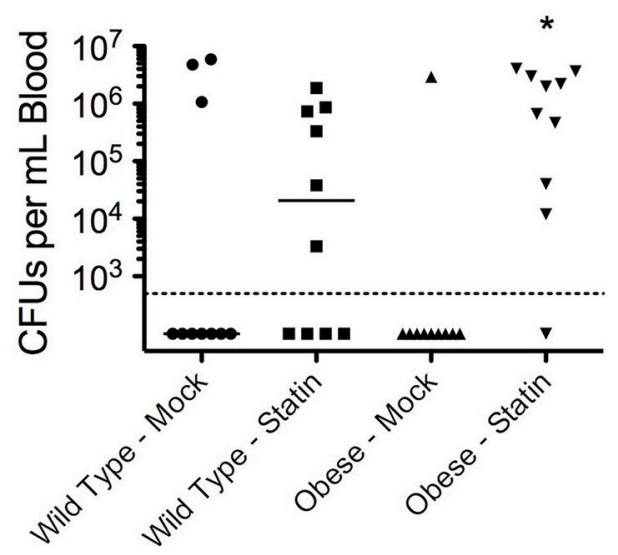

FIGURE 3 | Impact of statin intervention on pneumococcal pathogenesis in wild-type and obese mice. (A) Survival of wild-type mice receiving mock or statin supplemented diet following infection with pneumococcus $(p>0.05$ Mantel log-rank test). (B) Statin intervention significantly $(p<0.05$ Mantel log-rank test) reduced survival in obese mice following pneumococcal infection. (C) Statin invention significantly increased bacterial burden in the bloodstream in obese animals ( $p<0.05$, Mann-Whitney). $n=10$ mice per group. Note that statistical comparisons were made between each combination of two treatment groups to determine significance. *Indicates $p<0.05$.

with viral or bacterial infection, by influenza and S. pneumoniae respectively, may cancel each other out in the context of coinfection. 


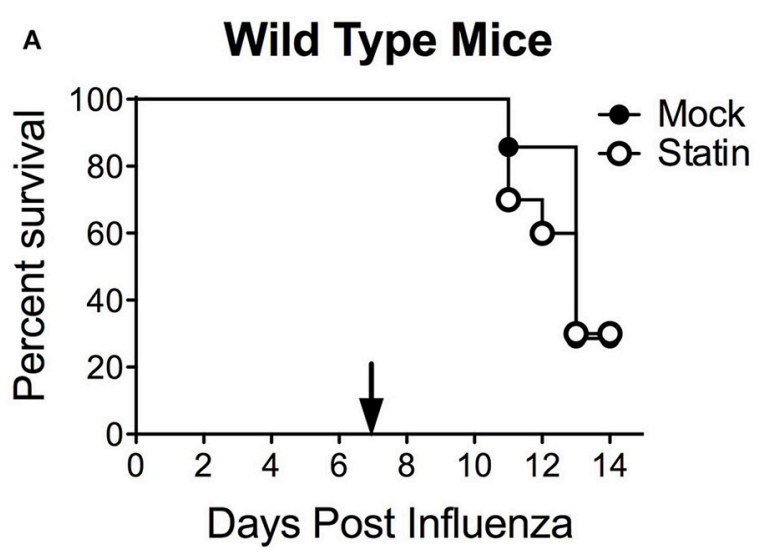

B Obese Mice

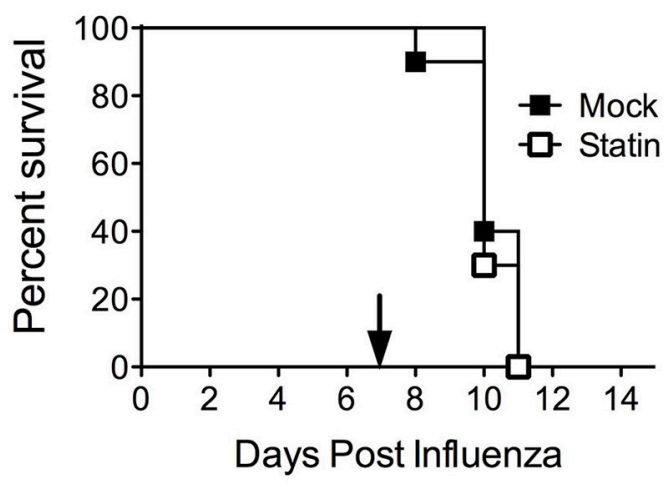

FIGURE 4 | Impact of statin intervention in a model of influenza-pneumococcal co-infection. Statin therapy did not significantly improve or reduce mortality in either wild-type (A) or obese (B) mice ( $\boldsymbol{D}>0.05$, Mantel log-rank test). $n=10$ mice per group. Arrow indicates day of challenge with $S$. pneumoniae.

There are several possible mechanisms that could contribute to the differences in statin-mediated alterations in obese but not wild-type animals. First of all, the lipid-altering effects of statins could be contributing to altered disease susceptibility. This is particularly relevant to the pneumococcus, as one of its major virulence factors is a cholesterol dependent cytolysin, pneumolysin, which could potentially be inhibited by high levels of serum cholesterol. To test this hypothesis, mice fed a high cholesterol diet, but which have a normal BMI, were infected with pneumococcus. The pneumococcal infection susceptibility was directly opposite from the obese phenotype with mice fed the high cholesterol diet being extremely susceptible to bacterial infection (Figure 5A). In contrast to the obese animals, the highcholesterol diet mice demonstrated heightened susceptibility to both $S$. pneumoniae and influenza infection (Figure 5B). These results are in support of previous findings that serum cholesterol levels may have an inverse relationship with influenza infection (Iribarren et al., 1997). These results are in contrast to the susceptibility of the obese animals to $S$. pneumoniae infection. This suggests factors independent of cholesterol levels are likely mediating the differences in susceptibility to infection in the context of statin prophylaxis in the obese murine models.

\section{A Influenza Challenge}

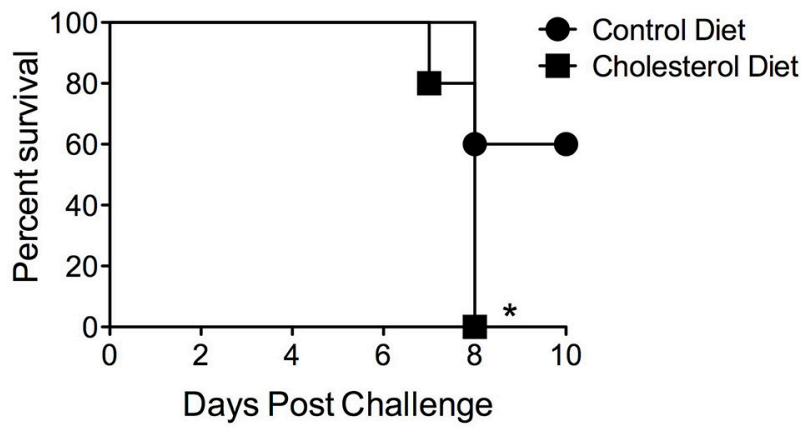

B Pneumococcal Challenge

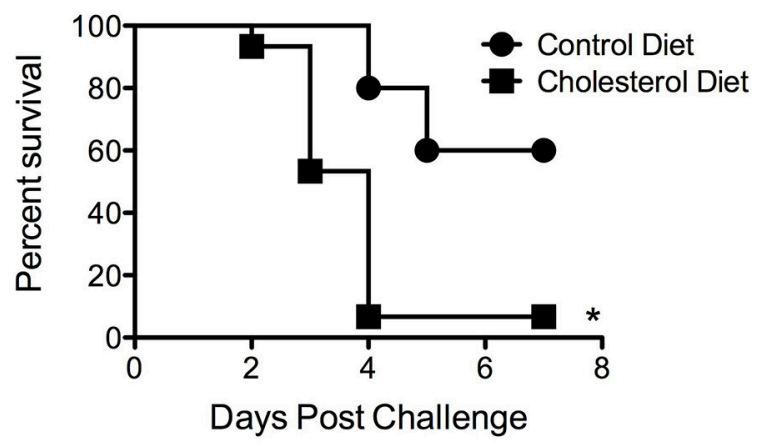

FIGURE 5 | Impact of cholesteremia on infection susceptibility. Mice fed a high cholesterol diet had significantly reduced mortality $(p<0.05$, Mantel log-rank test) compared to mice on the control diet in response to both influenza (A) and pneumococcal challenge (B). $n=10$ mice per group. *Indicates $p<0.05$.

\section{DISCUSSION}

The pleiotropic effects of statins with potential protective effects extending to pneumonia and sepsis have long been recognized. These effects have primarily been ascribed to their proposed immune modulatory functions, though the clinical data has been conflicted into the potential protective benefit despite large patient cohorts (Table 1 and reference therein). The inherent variability of patient populations on statin intervention, in particular metabolic status, could be a major confounding factor that many studies do not incorporate despite an accumulating amount of evidence of the impact of obesity on immune responses and infection susceptibility, particularly in the context of influenza infection (Green and Beck, 2017). This heightened infection risk in obese individuals is apparent despite current vaccination efforts (Neidich et al., 2017). Further confounding the situation is that diagnosing the etiological agents of pneumonia can be particularly challenging with considerable institutional variance (Murdoch et al., 2009). These confounders can be difficult to access from clinical data, as discerning between viral and bacterial pneumonia from chest $\mathrm{x}$-rays can be challenging (Graffelman et al., 2008). As such, the responsible infectious agents in such large clinical cohorts as many of the statin-related studies have compromised have been limited to 
TABLE 1 | Examples of the role of statin therapy on pneumonia.

\begin{tabular}{|c|c|c|c|c|c|c|}
\hline Year & Statin used & \# Participants & Protection & $\begin{array}{l}\text { Bacterial vs. } \\
\text { Viral }\end{array}$ & $\begin{array}{l}\text { Obesity } \\
\text { status }\end{array}$ & References \\
\hline 2008 & Non-specific & 5,772 & Y & $\mathrm{N}$ & $\mathrm{N}$ & Mortensen et al., 2008 \\
\hline 2009 & Non-specific & 3,681 & Y & $\mathrm{N}$ & $\mathrm{N}$ & Myles et al., 2009 \\
\hline 2008 & Simvastatin, atorvastatin, pravastatin & 1,007 & Y & $\mathrm{N}$ & $\mathrm{N}$ & Chalmers et al., 2008 \\
\hline 2011 & Non-specific & 129,288 & Y & $\mathrm{N}$ & $\mathrm{N}$ & Douglas et al., 2011 \\
\hline 2013 & Non-specific & 347 & Y & Viral only & $\mathrm{N}$ & Doshi et al., 2013 \\
\hline 2012 & Non-specific & 22,996 & Y & $\mathrm{N}$ & $\mathrm{N}$ & Mortensen et al., 2012 \\
\hline 2009 & Simvastatin, lovastatin, atorvastatin & 1,125 & $\mathrm{~N}$ & $\mathrm{~N}$ & $\mathrm{~N}$ & Dublin et al., 2009 \\
\hline 2007 & Non-specific & 76,232 & Y & Y & $\mathrm{N}$ & Frost et al., 2007 \\
\hline 2012 & Non-specific & 121,254 & Y & Y & Y & Rothberg et al., 2012 \\
\hline 2007 & Non-specific & 1,253 & Y & $\mathrm{N}$ & $\mathrm{N}$ & Schlienger et al., 2007 \\
\hline 2011 & Atorvastatin, simvastatin & 17,755 & Y & $\mathrm{N}$ & $\mathrm{N}$ & Vinogradova et al., 2011 \\
\hline 2008 & Simvastatin, atorvastatin, pravastatin & 29,900 & Y & $\mathrm{N}$ & $\mathrm{N}$ & Thomsen et al., 2008 \\
\hline 2011 & Simvastatin, atorvastatin, pravastatin, lovastatin, fluvastatin & 1,895 & $\mathrm{~N}$ & $\mathrm{~N}$ & $\mathrm{~N}$ & Yende et al., 2011 \\
\hline 2012 & Simvastatin, atorvastatin, pravastatin & 7,223 & Y & $\mathrm{N}$ & Y & Nielsen et al., 2012 \\
\hline 2012 & Rosuvastatin & 17,802 & Y & $\mathrm{N}$ & Y & Novack et al., 2012 \\
\hline 2011 & Pravastatin & 152 & Y & $\mathrm{N}$ & $\mathrm{N}$ & Novack et al., 2012 \\
\hline 2006 & Non-specific & 4,719 & Y & $\mathrm{N}$ & $\mathrm{N}$ & van de Garde et al., 2006 \\
\hline 2005 & Non-specific & 787 & Y & $\mathrm{N}$ & $\mathrm{N}$ & Mortensen et al., 2005 \\
\hline
\end{tabular}

sepsis and pneumonia without further discrimination based on the responsible pathogen.

The observation that statins were beneficial for a viral infection but detrimental for a bacterial infection in the context of obesity was an unexpected finding. Obesity is known to impact of number of immunologic processes though the mechanisms underlying these differences are mechanistically complex (Milner and Beck, 2012). One potential explanation is that the statins alter the inflammatory state as to favor the progression of bacterial but not viral pneumonia in obese individuals. During the pneumococcal pneumonia the inflammatory response consists of a rapid recruitment of neutrophils to mediate clearance of the bacteria and is an extremely rapid, acute response. Obesity can dramatically impact neutrophil migration through leptin signaling as well as impact neutrophil oxidative capabilities (Gainsford et al., 1996; Caldefie-Chezet et al., 2001, 2003). Leptin signaling in obesity has also been associated with the production of numerous pro-inflammatory cytokines, whose signaling play important roles in the initial phases of controlling pneumococcal pneumonia (Matarese et al., 2005). As such, if statins were decreasing production of such inflammatory cytokines, one might expect to observe heightened susceptibility to pneumococcal infection due to reduced initial bacterial clearance in obese animals.

In contrast to pneumococcal infection, mortality for the influenza infection typically occurred days later indicating this response may be more dependent more upon the adaptive immune response. It has been demonstrated that leptin can enhance for the proliferation and the activation of T-cells, though such stimulation was dependent upon a stimulatory co-factor (Martín-Romero et al., 2000). Leptin was also found to enhance the production of pro-inflammatory cytokines by T-cells as well as limit apoptosis in response to stress (Fujita et al., 2002; Lord et al., 2002). Simvastatin has been shown to modulate T-cell responses in models of airway inflammation such as asthma, but requires accessory cells for the observed effects (Liu et al., 2014; Knobloch et al., 2016). This modulation of adaptive immunity by statins in the context of obesity may play an important role in the observed protective effects observed in these animals.

Overall, these results indicate the need for controlling for both infection etiology as well as risk factors such as obesity during epidemiological studies to determine the groups who will benefit or possibly have increased risk of respiratory infection from the use of statins. Further work on the effects of statins on the pathogenesis and immunological responses against primary and co-infection with respiratory pathogens is warranted.

\section{AUTHOR CONTRIBUTIONS}

EK, SS-C, and JR designed the experiments, interpreted the data, and wrote the manuscript. EK and JR performed the experiments.

\section{FUNDING}

This work was supported by ALSAC. 


\section{REFERENCES}

Caldefie-Chezet, F., Poulin, A., and Vasson, M. P. (2003). Leptin regulates functional capacities of polymorphonuclear neutrophils. Free Radic. Res. 37, 809-814. doi: 10.1080/1071576031000097526

Caldefie-Chezet, F., Poulin, A., Tridon, A., Sion, B., and Vasson, M. P. (2001). Leptin: a potential regulator of polymorphonuclear neutrophil bactericidal action? J. Leukoc. Biol. 69, 414-418. doi: 10.1189/jlb.69.3.414

Chalmers, J. D., Singanayagam, A., Murray, M. P., and Hill, A. T. (2008). Prior statin use is associated with improved outcomes in community-acquired pneumonia. Am. J. Med. 121, 1002 e1-1007 el. doi: 10.1016/j.amjmed.2008.06.030

Cline, T. D., Karlsson, E. A., Freiden, P., Seufzer, B. J., Rehg, J. E., Webby, R. J., et al. (2011). Increased pathogenicity of a reassortant 2009 pandemic H1N1 influenza virus containing an H5N1 hemagglutinin. J. Virol. 85, 12262-12270. doi: 10.1128/JVI.05582-11

Doshi, S. M., Kulkarni, P. A., Liao, J. M., Rueda, A. M., and Musher, D. M. (2013). The impact of statin and macrolide use on early survival in patients with pneumococcal pneumonia. Am. J. Med. Sci. 345, 173-177. doi: 10.1097/MAJ.0b013e3182639c26

Douglas, I., Evans, S., and Smeeth, L. (2011). Effect of statin treatment on short term mortality after pneumonia episode: cohort study. BMJ 342:d1642. doi: 10.1136/bmj.d1642

Dublin, S., Jackson, M. L., Nelson, J. C., Weiss, N. S., Larson, E. B., and Jackson, L. A. (2009). Statin use and risk of community acquired pneumonia in older people: population based case-control study. BMJ 338:b2137. doi: $10.1136 /$ bmj.b2137

Easterbrook, J. D., Dunfee, R. L., Schwartzman, L. M., Jagger, B. W., Sandouk, A., Kash, J. C., et al. (2011). Obese mice have increased morbidity and mortality compared to non-obese mice during infection with the 2009 pandemic H1N1 influenza virus. Influenza Other Respir. Viruses 5, 418-425. doi: 10.1111/j.1750-2659.2011.00254.x

Fedson, D. S. (2006). Pandemic influenza: a potential role for statins in treatment and prophylaxis. Clin. Infect. Dis. 43, 199-205. doi: 10.1086/505116

Flegal, K. M., Carroll, M. D., Ogden, C. L., and Curtin, L. R. (2010). Prevalence and trends in obesity among US adults, 1999-2008. JAMA 303, 235-241. doi: 10.1001/jama.2009.2014

Francis, K. P., Yu, J., Bellinger-Kawahara, C., Joh, D., Hawkinson, M. J., Xiao, G., et al. (2001). Visualizing pneumococcal infections in the lungs of live mice using bioluminescent Streptococcus pneumoniae transformed with a novel gram-positive lux transposon. Infect. Immun. 69, 3350-3358. doi: 10.1128/IAI.69.5.3350-3358.2001

Frost, F. J., Petersen, H., Tollestrup, K., and Skipper, B. (2007). Influenza and COPD mortality protection as pleiotropic, dose-dependent effects of statins. Chest 131, 1006-1012. doi: 10.1378/chest.06-1997

Fujita, Y., Murakami, M., Ogawa, Y., Masuzaki, H., Tanaka, M., Ozaki, S., et al. (2002). Leptin inhibits stress-induced apoptosis of T lymphocytes. Clin. Exp. Immunol. 128, 21-26. doi: 10.1046/j.1365-2249.2002.01797.x

Gainsford, T., Willson, T. A., Metcalf, D., Handman, E., McFarlane, C., Ng, A., et al. (1996). Leptin can induce proliferation, differentiation, and functional activation of hemopoietic cells. Proc. Natl. Acad. Sci. U.S.A. 93, 14564-14568. doi: 10.1073 /pnas.93.25.14564

Graffelman, A. W., Willemssen, F. E., Zonderland, H. M., Neven, A. K., Kroes, A. C., and van den Broek, P. J. (2008). Limited value of chest radiography in predicting aetiology of lower respiratory tract infection in general practice. $\mathrm{Br}$. J. Gen. Pract. 58, 93-97. doi: 10.3399/bjgp08X264054

Green, W. D., and Beck, M. A. (2017). Obesity altered T cell metabolism and the response to infection. Curr. Opin. Immunol. 46, 1-7. doi: 10.1016/j.coi.2017.03.008

Iribarren, C., Jacobs, D. R. Jr., Sidney, S., Claxton, A. J., Gross, M. D., Sadler, M., et al. (1997). Serum total cholesterol and risk of hospitalization, and death from respiratory disease. Int. J. Epidemiol. 26, 1191-1202. doi: 10.1093/ije/26.6.1191

Jain, M. K., and Ridker, P. M. (2005). Anti-inflammatory effects of statins: clinical evidence and basic mechanisms. Nat. Rev. Drug. Discov. 4, 977-987. doi: $10.1038 / \mathrm{nrd} 1901$

Karlsson, E. A., and Beck, M. A. (2010). The burden of obesity on infectious disease. Exp. Biol. Med. 235, 1412-1424. doi: 10.1258/ebm.2010.0 10227
Karlsson, E. A., Meliopoulos, V. A., van de Velde, N. C., van de Velde, L. A., Mann, B., Gao, G., et al. (2017). A perfect storm: increased colonization and failure of vaccination leads to severe secondary bacterial infection in influenza virus-infected obese mice. mBio 8:e00889-17. doi: 10.1128/mBio.00889-17

Knobloch, J., Yakin, Y., Körber, S., Grensemann, B., Bendella, Z., Boyaci, N., et al. (2016). Simvastatin requires activation in accessory cells to modulate T-cell responses in asthma and COPD. Eur. J. Pharmacol. 788, 294-305. doi: 10.1016/j.ejphar.2016.06.037

Liu, J. N., Suh, D. H., Yang, E. M., Lee, S. I., Park, H. S., and Shin, Y. S., (2014). Attenuation of airway inflammation by simvastatin and the implications for asthma treatment: is the jury still out? Exp. Mol. Med. 46:e113. doi: $10.1038 / \mathrm{emm} .2014 .55$

Lord, G. M., Matarese, G., Howard, J. K., Bloom, S. R., and Lechler, R. I. (2002). Leptin inhibits the anti-CD3-driven proliferation of peripheral blood $\mathrm{T}$ cells but enhances the production of proinflammatory cytokines. J. Leukoc. Biol. 72, 330-338. doi: 10.1189/jlb.72.2.330

Lutz, T. A., and Woods, S. C. (2012). Overview of Animal Models of Obesity. Curr. Protoc. Pharmacol. Chapter Unit5.61-Unit5.61. doi: 10.1002/0471141755.ph0561s58

Martín-Romero, C., Santos-Alvarez, J., Goberna, R., and Sánchez-Margalet, V. (2000). Human leptin enhances activation and proliferation of human circulating $\mathrm{T}$ lymphocytes. Cell. Immunol. 199, 15-24. doi: 10.1006/cimm.1999.1594

Matarese, G., Moschos, S., and Mantzoros, C. S. (2005). Leptin in immunology. J. Immunol. 174, 3137-3142. doi: 10.4049/jimmunol.174.6.3137

McAuley, J. L., Hornung, F., Boyd, K. L., Smith, A. M., McKeon, R., Bennink, J., et al. (2007). Expression of the 1918 influenza A virus PB1-F2 enhances the pathogenesis of viral and secondary bacterial pneumonia. Cell Host Microbe 2, 240-249. doi: 10.1016/j.chom.2007.09.001

McCullers, J. A. (2014). The co-pathogenesis of influenza viruses with bacteria in the lung. Nat. Rev. Microbiol. 12, 252-262. doi: 10.1038/nrmicro3231

Milner, J. J., and Beck, M. A. (2012). The impact of obesity on the immune response to infection. Proc. Nutr. Soc. 71, 298-306. doi: 10.1017/S0029665112000158

Mortensen, E. M., Nakashima, B., Cornell, J., Copeland, L. A., Pugh, M. J., Anzueto, A., et al. (2012). Population-based study of statins, angiotensin II receptor blockers, and angiotensin-converting enzyme inhibitors on pneumonia-related outcomes. Clin. Infect. Dis. 55, 1466-1473. doi: 10.1093/cid/cis733

Mortensen, E. M., Pugh, M. J., Copeland, L. A., Restrepo, M. I., Cornell, J. E., Anzueto, A., et al. (2008). Impact of statins and angiotensin-converting enzyme inhibitors on mortality of subjects hospitalised with pneumonia. Eur. Respir. J. 31, 611-617. doi: 10.1183/09031936.00162006

Mortensen, E. M., Restrepo, M. I., Anzueto, A., and Pugh, J. (2005). The effect of prior statin use on 30-day mortality for patients hospitalized with communityacquired pneumonia. Respir. Res. 6:82. doi: 10.1186/1465-9921-6-82

Morton, D. B. (2000). A systematic approach for establishing humane endpoints. ILAR J. 41, 80-86. doi: 10.1093/ilar.41.2.80

Murdoch, D. R., O’Brien, K. L., Scott, J. A., Karron, R. A., Bhat, N., Driscoll, A. J., et al. (2009). Breathing new life into pneumonia diagnostics. J. Clin. Microbiol. 47, 3405-3408. doi: 10.1128/JCM.01685-09

Myles, P. R., Hubbard, R. B., Gibson, J. E., Pogson, Z., Smith, C. J., and McKeever, T. M. (2009). The impact of statins, ACE inhibitors and gastric acid suppressants on pneumonia mortality in a UK general practice population cohort. Pharmacoepidemiol. Drug Saf. 18, 697-703. doi: 10.1002/pds.1769

Neidich, S. D., Green, W. D., Rebeles, J., Karlsson, E. A., Schultz-Cherry, S., Noah, T. L., et al. (2017). Increased risk of influenza among vaccinated adults who are obese. Int. J. Obes. 41, 1324-1330. doi: 10.1038/ijo.2017.131

Nielsen, A. G., Nielsen, R. B., Riis, A. H., Johnsen, S. P., Sørensen, H. T., and Thomsen, R. W. (2012). The impact of statin use on pneumonia risk and outcome: a combined population-based case-control and cohort study. Crit. Care 16:R122. doi: 10.1186/cc11418

Novack, V., MacFadyen, J., Malhotra, A., Almog, Y., Glynn, R. J., and Ridker, P. M. (2012). The effect of rosuvastatin on incident pneumonia: results from the JUPITER trial. CMAJ 184, E367-E372. doi: 10.1503/cmaj.111017

O’Brien, K. B., Vogel, P., Duan, S., Govorkova, E. A., Webby, R. J., McCullers, J. A., et al. (2012). Impaired wound healing predisposes obese mice to severe influenza virus infection. J. Infect. Dis. 205, 252-261. doi: 10.1093/infdis/jir729

Reed, L. J., and Meunch, H. (1938). A simple method of estimating fifty percent endpoints. Am. J. Hyg. 27, 493-497. 
Rothberg, M. B., Bigelow, C., Pekow, P. S., and Lindenauer, P. K. (2012). Association between statins given in hospital and mortality in pneumonia patients. J. Gen. Intern. Med. 27, 280-286. doi: 10.1007/s11606-011-1826-2

Schlienger, R. G., Fedson, D. S., Jick, S. S., Jick, H., and Meier, C. R. (2007). Statins and the risk of pneumonia: a population-based, nested case-control study. Pharmacotherapy 27, 325-332. doi: 10.1592/phco.27.3.325

Smith, A. G., Sheridan, P. A., Harp, J. B., and Beck, M. A. (2007). Diet-induced obese mice have increased mortality and altered immune responses when infected with influenza virus. J. Nutr. 137, 1236-1243. doi: $10.1093 / \mathrm{jn} / 137.5 .1236$

Thomsen, R. W., Riis, A., Kornum, J. B., Christensen, S., Johnsen, S. P., and Sørensen, H. T. (2008). Preadmission use of statins and outcomes after hospitalization with pneumonia: population-based cohort study of 29,900 patients. Arch. Intern. Med. 168, 2081-2087. doi: 10.1001/archinte.168.19.2081

Tonstad, S., and Després, J. P. (2011). Treatment of lipid disorders in obesity. Expert Rev. Cardiovasc. Ther. 9, 1069-1080. doi: 10.1586/erc.11.83

van de Garde, E. M., Hak, E., Souverein, P. C., Hoes, A. W., van den Bosch, J. M., and Leufkens, H. G. (2006). Statin treatment and reduced risk of pneumonia in patients with diabetes. Thorax 61, 957-961. doi: 10.1136/thx.2006.062885
Vinogradova, Y., Coupland, C., and Hippisley-Cox, J. (2011). Risk of pneumonia in patients taking statins: population-based nested casecontrol study. Br. J. Gen. Pract. 61, e742-e748. doi: 10.3399/bjgp11X6 06654

Yende, S., Milbrandt, E. B., Kellum, J. A., Kong, L., Delude, R. L., Weissfeld, L. A., et al. (2011). Understanding the potential role of statins in pneumonia and sepsis. Crit. Care Med. 39, 1871-1878. doi: 10.1097/CCM.0b013e31821b8290

Conflict of Interest Statement: The authors declare that the research was conducted in the absence of any commercial or financial relationships that could be construed as a potential conflict of interest.

Copyright (C) 2018 Karlsson, Schultz-Cherry and Rosch. This is an open-access article distributed under the terms of the Creative Commons Attribution License (CC $B Y)$. The use, distribution or reproduction in other forums is permitted, provided the original author(s) and the copyright owner are credited and that the original publication in this journal is cited, in accordance with accepted academic practice. No use, distribution or reproduction is permitted which does not comply with these terms. 